\title{
Cross-Sectional Study Shows Kindergarten Barefoot Policy Positively Affects Soles' Contact Area
}

\author{
Shigeki Matsuda ${ }^{*}$, Kosho Kasuga ${ }^{2}$, Tadayuki Hanai ${ }^{3}$, Tomohiro Demura ${ }^{4}$ \\ ${ }^{1}$ Faculty of Education, Shiga University, Otsu, Japan \\ ${ }^{2}$ Faculty of Education, Gifu University, Gifu, Japan \\ ${ }^{3}$ Department of Early Childhood Education, Chubu University, Kasugai, Japan \\ ${ }^{4}$ Faculty of Human Life Studies, Jin-ai University, Echizen, Japan \\ Email: *matsuda@edu.shiga-u.ac.jp
}

How to cite this paper: Matsuda, S., Kasuga, K., Hanai, T., \& Demura, T. (2018). Cross-Sectional Study Shows Kindergarten Barefoot Policy Positively Affects Soles' Contact Area. Advances in Physical Education, 8, 295-307.

https://doi.org/10.4236/ape.2018.83026

Received: July 5, 2018

Accepted: July 30, 2018

Published: August 2, 2018

Copyright (c) 2018 by authors and Scientific Research Publishing Inc. This work is licensed under the Creative Commons Attribution-NonCommercial International License (CC BY-NC 4.0). http://creativecommons.org/licenses/by-nc/4.0/

cc) (i) (8) Open Access

\begin{abstract}
Although some studies have examined the effect of allowing preschool children to go without shoes, some points remain unexamined. Therefore, this study examined the effect of kindergartens' barefoot policy on the contact area of the soles of the feet (plantar arch, hallux valgus angle, and foot angle). Participants were 313 preschool children (169 boys; 144 girls) at a kindergarten following the barefoot policy and 339 (176 boys; 163 girls) at a kindergarten not following the policy. The children stood barefoot on a pedoscope, so images of their soles' contact area could be taken and then analyzed by software specifically for that purpose. Both boys and girls who attended kindergartens with barefoot policy had better development of the plantar arch and less angle of the hallux valgus than children who attended kindergartens not following the barefoot policy. Only boys who attended kindergartens that followed barefoot policy had a larger foot angle than children who attended kindergartens that did not. For preschool children, barefoot policy positively affected their soles' contact area.
\end{abstract}

\section{Keywords}

Barefoot Policy, Preschool Children, Preschool, Kindergarten, Plantar Arch, Hallux Valgus, Foot Angle

\section{Introduction}

Some kindergartens in Japan follow a barefoot policy that is generally considered to have good effects for children's growth, development, and health. After child- 
ren arrive at their kindergartens, they remove their shoes to play barefoot. However, some people oppose the barefoot policy because children can be easily injured and because following barefoot policy in winter is difficult. In fact, pros and cons of the barefoot policy have not yet been sufficiently examined, so its effects need multilateral investigation to provide factual information for parents and guardians, kindergarten staff, and so on. If barefoot policy's effects are clearly detailed multilaterally, parents and guardians can more easily judge whether to enroll their children in kindergartens following barefoot policy, and kindergarten staff can more easily judge whether to adopt barefoot policy.

Previous studies have reported effects of barefoot policy on "non-touching" toes, those that do not touch the ground during standing, and the anterior-posterior foot pressure ratio (Matsuda, Kasuga, Hanai, \& Demura, 2016; Matsuda, Kasuga, Hanai, Demura, \& Futabayashi, 2016; Matsuda, Kasuga, Hanai, Demura, \& Komura, 2016). Research revealed that boys who attended kindergartens following barefoot policy had fewer non-touching toes and lower posterior foot pressure ratio than those who attended kindergartens not following the policy (Matsuda, Kasuga, Hanai, \& Demura, 2016; Matsuda, Kasuga, Hanai, Demura, \& Futabayashi, 2016; Matsuda, Kasuga, Hanai, Demura, \& Komura, 2016). Although some effects of barefoot policy have been previously examined, its effects require multilateral examination in order to judge pros and cons comprehensively. Hence, some effects still require investigation.

Because human beings' contact sole is the only bodily region that touches the ground when standing, walking, and running, it plays an important role in maintaining posture and locomotion (Hughes, Clark, \& Klenerman, 1990; Tsung, Zhang, Fan, \& Boone, 2003). Children attending kindergartens following barefoot policy spend much less time with shoes compressing their feet, so they can move their feet more freely (Wegener, Hunt, Vanwanseele, Burns, \& Smith, 2011). Possibly then, the soles' contact area differs between children who attend kindergartens following barefoot policy and those who attend kindergartens that do not follow the policy. However, the barefoot policy's effect on the soles' contact area has not been sufficiently examined.

First, an important part of the soles' contact area is the plantar arch because it functions to absorb impact. Thus, the plantar arch should be well developed and shaped during childhood (Forriol \& Pascual, 1990; Volpon, 1994). Reports have stated that flat feet, in which the plantar arch is not well shaped, relate to the toes' muscle weakness (Tashiro et al., 2015), obesity, and the soles' fatigue and pain (Otsuka et al., 2003; Riddiford-Harland, Steele, \& Storlien, 2000; Sachithanandam \& Joseph, 1995). People who go barefoot for years have better plantar arch development than those who wear shoes (Echarri \& Forriol, 2003; Rao \& Joseph, 1992; Sachithanandam \& Joseph, 1995). Therefore, formation of children's plantar arch should be examined in relation to going barefoot.

Second, young people in Japan tend to have increased hallux valgus, commonly called "bunion” in English (Sato, Umemura, \& Masaki, 2003; Shimoeda, 
Sato, \& Sano, 1995). Although heredity can cause hallux valgus (Lee et al., 2014), wearing shoes is also a major cause (Klein, Groll-Knapp, Kundi, \& Kinz, 2009; Menz et al., 2016). Possibly children who attend kindergartens with barefoot policy do not tend toward hallux valgus because they play barefoot for a long time and frequently use their toes, which are not compressed by shoes. Highly possible also is that barefoot policy affects the toes' shape because children who attend kindergartens with barefoot policy have fewer non-touching toes (Matsuda, Kasuga, Hanai, \& Demura, 2016; Matsuda, Kasuga, Hanai, Demura, \& Komura, 2016). In addition, although a relationship between hallux valgus and flat feet has been reported (Kalen \& Brecher, 1988; Nguyen et al., 2010), few studies have investigated this relationship in children and the effect of barefoot policy on the relationship.

Third, many studies have reported that gait differs between going barefoot and wearing shoes (Franklin, Grey, Heneghan, Bowen, \& Li, 2015; Lythgo, Wilson, \& Galea, 2009; Wegener et al., 2011). One difference includes foot pressure on the soles, that is, pressure and width of the anterior part of the feet's soles become larger when walking barefoot than when walking with shoes (Wolf et al., 2008). Possibly then, anterior soles are larger in children who attend kindergartens with barefoot policy. Therefore, this study examined the effect of kindergartens' barefoot policy on the contact area of the soles of the feet (plantar arch, hallux valgus angle, and foot angle).

\section{Methods}

\subsection{Participants}

Participants were 313 preschool children (169 boys; 144 girls) at kindergartens following the barefoot policy (barefoot group) and 339 (176 boys; 163 girls) at kindergartens not following the policy (non-barefoot group). Participants were classified in half-year groups by age (e.g., children who had reached their fifth birthday but were not yet 5 years, 6 months were placed in the 5.0 category; Table 1). Five- and six-year-olds in the barefoot group played barefoot in kindergartens throughout the year. Three-year-olds in the barefoot group wore indoor shoes only in winter, i.e., from January to March, because they were not used to being barefoot. In the non-barefoot group, participants wore indoor shoes while

Table 1. Number of participants.

\begin{tabular}{ccccccc}
\hline & & 5.0 -year & 5.5 -year & 6.0 -year & 6.5 -year & Total \\
\hline \multirow{2}{*}{ Barefoot group } & Goys & 44 & 45 & 55 & 25 & 169 \\
& Girls & 48 & 31 & 42 & 23 & 144 \\
& Sum & 92 & 76 & 97 & 48 & 313 \\
Non-barefoot & Boys & 31 & 50 & 48 & 47 & 176 \\
\cline { 2 - 4 } & Girls & 51 & 38 & 35 & 39 & 163 \\
\hline
\end{tabular}


playing in kindergartens.

Table 2 displays participants' characteristics. Two-way ANOVA (analysis of variance; group $\times$ age) was conducted for age, height, and body weight, with significant differences revealed in these parameters for both boys and girls; additionally, these parameters increased with age. The non-barefoot group had significantly higher body weight than the barefoot group.

The Ethics Committee on Human Experimentation of the Faculty of Human Science, Kanazawa University (2012-5) approved this experimental protocol.

\subsection{Measurement of the Sole's Contact Surface Area}

A pedoscope (Sakamoto, Japan) was used to record the contact area of participants'

Table 2. Participants' characteristics.

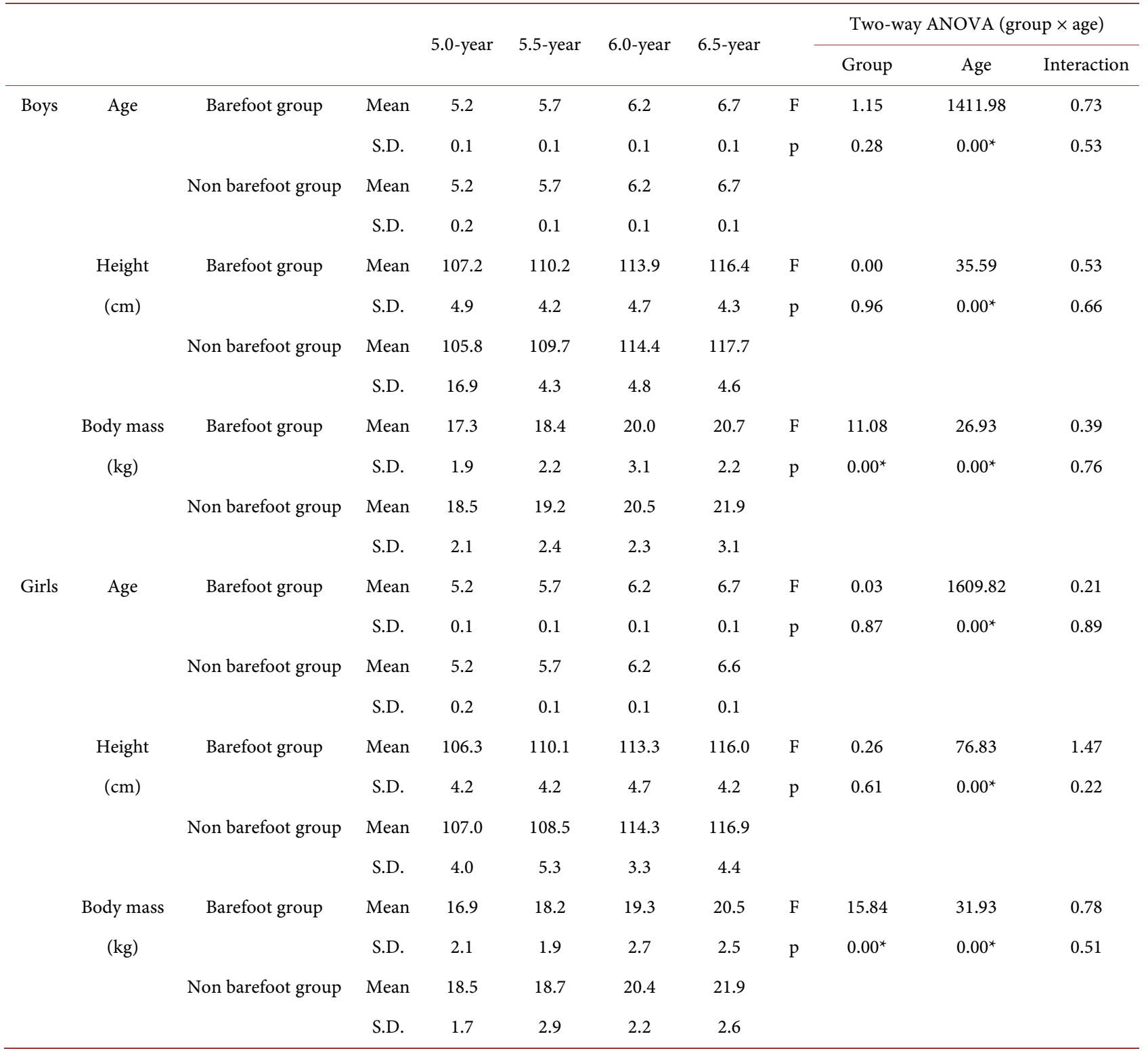

Note $)^{*}: p<0.05$. 
soles. Children stood barefoot on the pedoscope with their feet $5 \mathrm{~cm}$ apart and their hands relaxed at their sides. They were instructed to look at a mark at eye-level and to remain as still as possible during the measurement. After a tester-a university teacher-confirmed participants' postural stability, the pedoscope recorded a picture of the soles' contact surface area. Each participant was sequentially measured five times. A picture randomly selected among the five was analyzed by software from Amisystems, Japan, which was specifically designed for that purpose.

\subsection{Evaluation Variables for the Sole's Contact Area}

Figure 1 shows evaluation variables for the sole's contact area. As in previous studies (Harada, 2001), the $\mathrm{H}$ line was used to evaluate the plantar arch. The distance from the $\mathrm{H}$ line to the plantar arch's deepest point was used to evaluate the extent of plantar arch formation, and if the plantar arch's deepest point was located over the $\mathrm{H}$ line, it evidenced "accomplishment of plantar arch". With reference to previous studies (Klein et al., 2009; Okuda, Juman, Ueda, Miki, \& Shima, 2014), the hallux valgus angle-the degree of angle between the touching line to the hallux and inside line-was used to evaluate the extent of hallux valgus. Foot angle-the degree of angle between inside and outside lines-was used to evaluate whether the anterior foot area has spread or not. When the foot angle's numerical value is high, the anterior foot area's width is considered large.

\subsection{Statistical Analysis}

Two-way analysis of variance was conducted to examine differences between the barefoot and non-barefoot groups and among age groups for $\mathrm{H}$ line distance, hallux valgus angle, and foot angle. If analysis of variance showed a significant difference, Tukey's honest significant difference (HSD) test was used for multiple comparisons. The independence test was used to examine differences

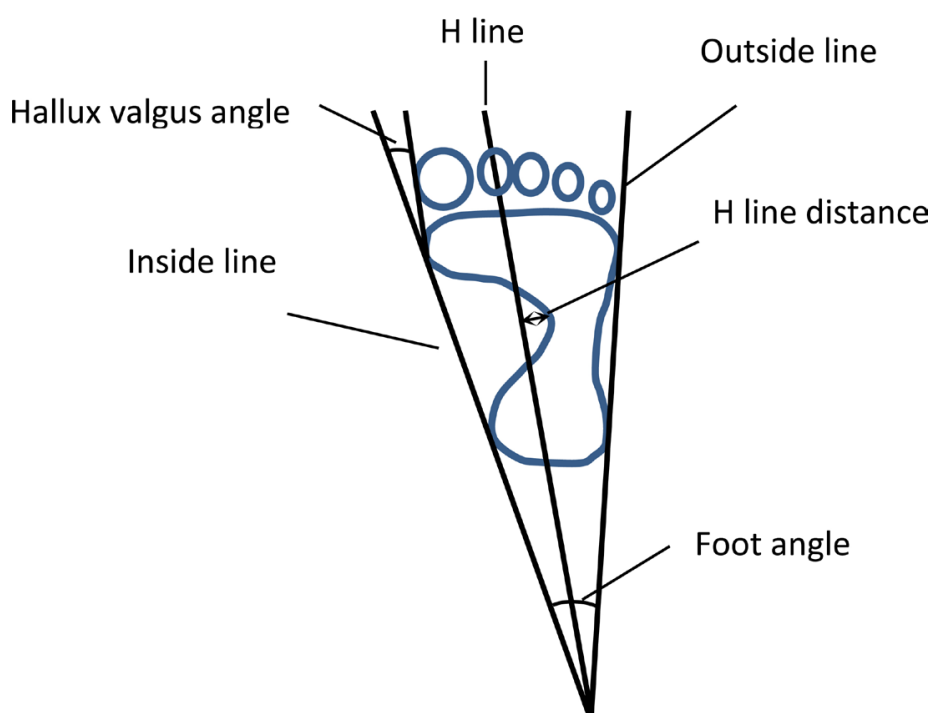

Figure 1. Evaluation variables for the sole's contact area anterior-posterior foot pressure ratio. 
between the two groups for accomplishment of plantar arch. Pearson's correlation coefficients were calculated to examine the relationship between $\mathrm{H}$ line distance and hallux valgus angle. Tests of correlation coefficients' differences were conducted to examine the difference between the two groups for correlation coefficients. The level of statistical significance was set at $p<0.05$.

\section{Results}

Table 3 shows results of two-way analysis of variance in $\mathrm{H}$ line distance, hallux valgus angle, and foot angle. Significant differences in boys and girls between groups were found in $\mathrm{H}$ line distance and hallux valgus angle. $\mathrm{H}$ line distance was higher in the barefoot group than in the non-barefoot group. Hallux valgus angle was higher in the non-barefoot group than in the barefoot group. Even

Table 3. Results of two-way analysis of variance in $\mathrm{H}$ line distance, hallux valgus angle, and foot angle.

\begin{tabular}{|c|c|c|c|c|c|c|c|c|c|c|c|}
\hline & & & & \multirow{2}{*}{5.0 -year } & \multirow{2}{*}{ 5.5-year } & \multirow{2}{*}{ 6.0-year } & \multirow{2}{*}{ 6.5-year } & & \multicolumn{3}{|c|}{ Two-way ANOVA (group × age) } \\
\hline & & & & & & & & & Group & Age & Interaction \\
\hline \multirow[t]{12}{*}{ Boys } & $\mathrm{H}$ line distance & Barefoot group & Mean & 0.52 & 0.68 & 0.97 & 0.95 & $\mathrm{~F}$ & 5.34 & 2.92 & 1.06 \\
\hline & $(\mathrm{cm})$ & & S.D. & 0.80 & 0.66 & 0.60 & 0.49 & $\mathrm{p}$ & $0.02^{\star}$ & $0.03^{*}$ & 0.37 \\
\hline & & Non barefoot group & Mean & 0.49 & 0.59 & 0.59 & 0.69 & & & & \\
\hline & & & S.D. & 0.78 & 0.90 & 0.79 & 0.80 & & & & \\
\hline & Hallux valgus angle & Barefoot group & Mean & 4.30 & 4.03 & 2.78 & 2.83 & $\mathrm{~F}$ & 9.82 & 1.40 & 0.23 \\
\hline & $\left({ }^{\circ}\right)$ & & S.D. & 4.52 & 5.05 & 5.70 & 4.76 & $\mathrm{p}$ & $0.00^{*}$ & 0.24 & 0.88 \\
\hline & & Non barefoot group & Mean & 5.26 & 5.98 & 4.93 & 4.65 & & & & \\
\hline & & & S.D. & 5.02 & 4.83 & 4.78 & 4.57 & & & & \\
\hline & Foot angle & Barefoot group & Mean & 17.24 & 18.27 & 18.38 & 17.90 & $\mathrm{~F}$ & 5.39 & 0.90 & 1.17 \\
\hline & $\left({ }^{\circ}\right)$ & & S.D. & 2.56 & 2.56 & 2.39 & 2.40 & $\mathrm{p}$ & $0.02^{*}$ & 0.44 & 0.32 \\
\hline & & Non barefoot group & Mean & 17.44 & 17.53 & 17.18 & 17.08 & & & & \\
\hline & & & S.D. & 2.20 & 2.18 & 3.10 & 2.16 & & & & \\
\hline \multirow[t]{12}{*}{ Girls } & $\mathrm{H}$ line distance & Barefoot group & Mean & 0.96 & 0.88 & 1.15 & 1.41 & $\mathrm{~F}$ & 4.97 & 6.10 & 1.76 \\
\hline & $(\mathrm{cm})$ & & S.D. & 0.58 & 0.73 & 0.45 & 0.51 & $\mathrm{p}$ & $0.03^{\star}$ & $0.00^{*}$ & 0.15 \\
\hline & & Non barefoot group & Mean & 0.76 & 1.01 & 0.88 & 1.14 & & & & \\
\hline & & & S.D. & 0.75 & 0.51 & 0.43 & 0.61 & & & & \\
\hline & Hallux valgus angle & Barefoot group & Mean & 0.38 & -0.39 & 1.34 & 2.44 & $\mathrm{~F}$ & 12.60 & 1.25 & 0.84 \\
\hline & $\left({ }^{\circ}\right)$ & & S.D. & 5.04 & 6.25 & 5.58 & 5.15 & $\mathrm{p}$ & $0.00^{*}$ & 0.29 & 0.47 \\
\hline & & Non barefoot group & Mean & 2.60 & 3.27 & 3.97 & 3.05 & & & & \\
\hline & & & S.D. & 4.84 & 6.01 & 5.45 & 5.62 & & & & \\
\hline & Foot angle & Barefoot group & Mean & 16.80 & 17.85 & 17.19 & 16.47 & $\mathrm{~F}$ & 0.25 & 2.21 & 2.16 \\
\hline & $\left({ }^{\circ}\right)$ & & S.D. & 2.52 & 2.23 & 2.55 & 1.85 & $\mathrm{p}$ & 0.62 & 0.09 & 0.09 \\
\hline & & Non barefoot group & Mean & 17.24 & 17.31 & 16.16 & 17.06 & & & & \\
\hline & & & S.D. & 2.37 & 2.29 & 2.21 & 1.83 & & & & \\
\hline
\end{tabular}

Note $)^{*}: p<0.05$. 
though significant age difference was found in boys' $\mathrm{H}$ line distance, multiple comparison tests revealed no significant difference. Significant age difference in girls' $\mathrm{H}$ line distance and higher values in 6.5-year-olds than in 5.0- and 5.5-year-olds were found. Significant difference between groups was found in boys' foot angle-higher in the barefoot than in the non-barefoot group.

Table 4 shows the number and percentage of children who had accomplishment of plantar arch and results of the independence test: boys' plantar arch accomplishment was $89.3 \%$ for the barefoot group and $78.4 \%$ for the non-barefoot group; the corresponding percentages for girls were $95.8 \%$ for the barefoot group and $94.5 \%$ for the non-barefoot group. The independence test showed that only boys' percentages had significant difference in accomplishment of the plantar arch.

Correlation coefficients between boys' $\mathrm{H}$ line distance and hallux valgus angle were $\mathrm{r}=-0.22(p=0.00)$ for the barefoot group and $\mathrm{r}=-0.24(p=0.00)$ for the non-barefoot group; the corresponding statistics for girls were $\mathrm{r}=-0.23$ ( $p=$ $0.00)$ for the barefoot group and $\mathrm{r}=-0.37(p=0.00)$ for the non-barefoot group. All these correlation coefficients were significant. Tests of correlation coefficients between the two groups did not find significant differences in boys and girls (boys: $\mathrm{z}=0.19, p=0.85$; girls: $\mathrm{z}=1.32, p=0.19$ ).

\section{Discussion}

Because the plantar arch forms markedly during childhood (Forriol \& Pascual, 1990;

Table 4. Results of two-way analysis of variance in $\mathrm{H}$ line distance, hallux valgus angle, and foot angle.

\begin{tabular}{|c|c|c|c|c|c|c|c|c|c|c|}
\hline & & & & 5.0-year & 5.5-year & 6.0-year & 6.5 -year & Total & $x^{2}$ & $p$ \\
\hline \multirow[t]{8}{*}{ Boys } & Barefoot group & Formed & $\mathrm{n}$ & 34 & 41 & 53 & 23 & 151 & 7.59 & $0.01^{*}$ \\
\hline & & & $\%$ & 77.3 & 91.1 & 96.4 & 92.0 & 89.3 & & \\
\hline & & Unformed & $\mathrm{n}$ & 10 & 4 & 2 & 2 & 18 & & \\
\hline & & & $\%$ & 22.7 & 8.9 & 3.6 & 8.0 & 10.7 & & \\
\hline & Non barefoot group & Formed & $\mathrm{n}$ & 22 & 39 & 39 & 38 & 138 & & \\
\hline & & & $\%$ & 71.0 & 78.0 & 81.3 & 80.9 & 78.4 & & \\
\hline & & Unformed & $\mathrm{n}$ & 9 & 11 & 9 & 9 & 38 & & \\
\hline & & & $\%$ & 29.0 & 22.0 & 18.8 & 19.1 & 21.6 & & \\
\hline \multirow[t]{8}{*}{ Girls } & Barefoot group & Formed & $\mathrm{n}$ & 46 & 27 & 42 & 23 & 138 & 0.30 & 0.58 \\
\hline & & & $\%$ & 95.8 & 87.1 & 100.0 & 100.0 & 95.8 & & \\
\hline & & Unformed & $\mathrm{n}$ & 2 & 4 & 0 & 0 & 6 & & \\
\hline & & & $\%$ & 4.2 & 12.9 & 0.0 & 0.0 & 4.2 & & \\
\hline & Non barefoot group & Formed & $\mathrm{n}$ & 45 & 37 & 35 & 37 & 154 & & \\
\hline & & & $\%$ & 88.2 & 97.4 & 100.0 & 94.9 & 94.5 & & \\
\hline & & Unformed & $\mathrm{n}$ & 6 & 1 & 0 & 2 & 9 & & \\
\hline & & & $\%$ & 11.8 & 2.6 & 0.0 & 5.1 & 5.5 & & \\
\hline
\end{tabular}

Note) $)^{*} p<0.05$. 
Volpon, 1994), this time period is crucial for its proper development. In fact, plantar arch formation proceeds as the soles' fat tissue decreases when children learn to walk (Volpon, 1994). In this study, $\mathrm{H}$ line distance was significantly higher for boys and girls in the barefoot group than for those in the non-barefoot one, suggesting that the plantar arch forms better in children who attend kindergartens with barefoot policy. Moreover, shoes restrict the foot's movement when walking (Wolf et al., 2008), so children playing barefoot have greater opportunity to move their feet freely. The windlass mechanism-the medial longitudinal arch becomes high as the plantar aponeurosis tenses and the calcaneus is pulled forward when the metatarsophalangeal joint extends-works when walking and running (Hasegawa et al., 2007; Hicks, 1954; Wegener et al., 2011; Wolf et al., 2008). Wolf et al. (2008) also reported that the plantar arch's length changes more significantly when walking barefoot than when wearing shoes. Thus, barefoot children's plantar arch likely develops better because their windlass mechanism works more frequently.

Some researchers have conducted studies about the relationship between going barefoot and the plantar arch. Rao \& Joseph (1992) reported that 4- to 13-year-old children who wore shoes continually had a higher percentage of flat feet (8.6\%) than those going barefoot (2.8\%). Sachithanandam \& Joseph (1995) reported a lower rate of flat feet in people beginning to wear shoes after age 16 than in those who wore them before age 16 , and in people who had worn shoes less than 8 hours a day than in those who wore shoes over 8 hours a day before they were 6 years old. These researchers concluded that a relationship exists between wearing shoes and flat feet, and the current study's results are similar to these previous studies' results. Evidence strongly suggests that going barefoot during childhood - when the feet are developing (Forriol \& Pascual, 1990; Volpon, 1994) - positively affects formation of the plantar arch. Flat feet, in which the plantar arch has not formed, have some negative effects, for instance, muscle weakness in the toes and fatigue and pain in the soles (Otsuka et al., 2003; Tashiro et al., 2015). Barefoot policy avoids these negative effects by encouraging healthy development of the plantar arch.

Although boys' rates of plantar arch development showed significant difference between barefoot and non-barefoot groups, girls' rates showed no difference. The plantar arch forms earlier in girls than in boys (Asami, Ishijima, Shibukawa, \& Miyazaki, 1987). Hence, the plantar arch formed even for girls who attended kindergartens without barefoot policy. In contrast, boys whose plantar arch had been completed were few in those who attended kindergartens without barefoot policy.

For boys and girls, the hallux valgus angle was significantly higher in the non-barefoot group than in the barefoot group. In Japan, the increased number of people with hallux valgus is due to wearing shoes (Kato \& Watanabe, 1981; Kusumoto, Suzuki, Kumakura, \& Ashizawa, 1996). Menz et al. (2016) reported that wearing tight shoes from age 20 to 39 leads to hallux valgus. Klein et al. 
(2009) also reported a relationship between wearing too-short shoes and hallux valgus angle. Thus, children who attend kindergartens following barefoot policy have fewer tendencies toward hallux valgus than children who continually wear shoes. Presumably, barefoot policy also positively affects the shape of the hallux. Children should not have a tendency to hallux valgus because it causes pain and affects movement negatively (Okuda et al., 2014).

This study also found significant negative correlation between $\mathrm{H}$ line distance and hallux valgus angle, suggesting that the plantar arch does not form well in children with a larger hallux valgus angle. Too, some previous studies have reported a relationship between flat feet and hallux valgus (Kalen \& Brecher, 1988; Nguyen et al., 2010). Kalen \& Brecher (1988) reported that adolescents who have hallux valgus also have concurrently flat feet 8 to 24 times. If the hallux is the appropriate shape, the plantar arch forms as the hallux is dorsiflexed appropriately and as the windlass mechanism works during walking and running (Hicks, 1954). Conversely, if the hallux valgus angle is large, plantar arch formation will be curbed because the hallux is not dorsiflexed and not used appropriately and because the windlass mechanism does not work when walking and running. Such factors are considered to underlie relationships between the plantar arch and hallux valgus. However, there was no significant difference between groups in correlation coefficients between $\mathrm{H}$ line distance and hallux valgus, so barefoot policy does not seem to affect the relationship between the plantar arch and hallux valgus.

Only in boys, the foot angle was significantly larger in the barefoot than in the non-barefoot group, suggesting that boys who attended kindergartens with barefoot policy had a larger anterior sole than boys who attended kindergartens without barefoot policy. Many previous studies have reported that gait differs between going barefoot and wearing shoes (Franklin et al., 2015; Lythgo et al., 2009; Wegener et al., 2011). Although wearing shoes promotes a landing pattern using the posterior sole (heel) because shoes weaken landing impact when walking (Wegener et al., 2011), going barefoot shows a landing pattern using the anterior sole (Lieberman et al., 2010). In addition, the anterior soles' pressure and width become larger when walking barefoot than when walking with shoes (Wolf et al., 2008). Due to these differences of gait, boys who attended kindergartens with barefoot policy tended to have larger anterior soles.

In fact, the inverted trapezoid foot-with large anterior soles-provides good balance and is appropriate for maintaining posture and for movement (Harada, Hasegawa, \& Sakashita, 1995). Hence, boys who attended kindergartens following barefoot policy had better contact surface area of the soles. On the other hand, girls' foot angle showed no significant difference. The barefoot policy's effects were found in non-touching toes and anterior-posterior foot pressure ratio only for boys (Matsuda, Kasuga, Hanai, \& Demura, 2016; Matsuda, Kasuga, Hanai, Demura, \& Futabayashi, 2016; Matsuda, Kasuga, Hanai, Demura, \& Komura, 2016). In other words, gender differences may exist in effects of barefoot pol- 
icy. Because boys tend to move more and more intensely than girls (Hinkley, Crawford, Salmon, Okely, \& Hesketh, 2008), gender differences in quantity and quality of movement may cause differing effects of barefoot policy.

This study has some limitations; first, that it was cross-sectional. A longitudinal study will be necessary to examine minutely and strictly barefoot policy's effect on the soles' contact area. Second, this study could not consider quantity of movement and barefoot status at home-factors that might change effects of barefoot policy on the soles' contact area. Therefore, future studies should include these factors when investigating effects of going barefoot.

\section{Conclusion}

This study examined the effect of kindergartens' barefoot policy on the soles' contact area (plantar arch, hallux valgus angle, and foot angle). Both boys and girls who attended kindergartens with the barefoot policy had better development of the plantar arch and less angle of the hallux valgus than children who attended kindergartens not following barefoot policy. Only boys who attended kindergartens following barefoot policy had an appropriately inverted trapezoid foot, in which anterior soles were appropriately large. For preschool children, barefoot policy positively affected the soles' contact area.

\section{Acknowledgements}

The authors wish to thank the subjects for their kind cooperation. This study was supported by a part of JSPS KAKENHI Grant Number 26350951 and 17K01894.

\section{Authors' Contributions}

MS controlled this study, performed the experiment, analyzed the data, and wrote the manuscript. KK cooperated with assembling the subjects and conducting the measurement and helped to draft the manuscript. HT cooperated with assembling the subjects and conducting the measurement. DT cooperated with assembling the subjects and conducting the measurement.

\section{Competing Interests}

The authors declare that they have no competing interests.

\section{References}

Asami, T., Ishijima, S., Shibukawa, K., \& Miyazaki, T. (1987). A Follow-Up Study on the Development of Foot Contact Area of Boys and Girls. Report of Research Center in Physical Education, 15, 113-125. (In Japanese)

Echarri, J. J., \& Forriol, F. (2003). The Development in Footprint Morphology in 1851 Congolese Children from Urban and Rural Areas, and the Relationship between This and Wearing Shoes. Journal of Pediatric Orthopedics Part B, 12, 141-146.

Forriol, F., \& Pascual, J. (1990). Footprint Analysis between Three and Seventeen Years of Age. Foot Ankle, 11, 101-104. https://doi.org/10.1177/107110079001100208 
Franklin, S., Grey, M. J., Heneghan, N., Bowen, L., \& Li, F. X. (2015). Barefoot vs Common Footwear: A Systematic Review of the Kinematic, Kinetic and Muscle Activity Differences during Walking. Gait \& Posture, 42, 230-239. https://doi.org/10.1016/j.gaitpost.2015.05.019

Harada, S. (2001). A Study on Physical Structures of Preschool Children's feet Compared between 1980 and 2000. Kutsuno Igaku, 15, 14-18. (In Japanese)

Harada, S., Hasegawa, S., \& Sakashita, K. (1995). Motor Ability and Development of Feet in Preschool Children. The Journal of Education and Health Science, 40, 171-180. (In Japanese)

Hasegawa, M., Kanai, S., Shimizu, M. E., Shimatani, K., Tanaka, S., Oki, S., \& Otsuka, A. (2007). The Influence of Footwear on the Windlass Mechanism and Toe Movement. Co-Medical Research Society of Structure and Function, 5, 75-80. (In Japanese)

Hicks, J. H. (1954). The Mechanics of the Foot. II. The Plantar Aponeurosis and the Arch. Journal of Anatomy, 88, 25-30.

Hinkley, T., Crawford, D., Salmon, J., Okely, A. D., \& Hesketh, K. (2008). Preschool Children and Physical Activity: A Review of Correlates. American Journal of Preventive Medicine, 34, 435-441. https://doi.org/10.1016/j.amepre.2008.02.001

Hughes, J., Clark, P., \& Klenerman, L. (1990). The Importance of the Toes in Walking. Journal of Bone and Joint Surgery, 72, 245-251. https://doi.org/10.1302/0301-620X.72B2.2312564

Kalen, V., \& Brecher, A. (1988). Relationship between Adolescent Bunions and Flatfeet. Foot \& Ankle, 8, 331-336. https://doi.org/10.1177/107110078800800609

Kato, T., \& Watanabe, S. (1981). The Etiology of Hallux Valgus in Japan. Clinical Orthopaedics and Related Research, 157, 78-81. https://doi.org/10.1097/00003086-198106000-00014

Klein, C., Groll-Knapp, E., Kundi, M., \& Kinz, W. (2009). Increased Hallux Angle in Children and Its Association with Insufficient Length of Footwear: A Community Based Cross-Sectional Study. BMC Musculoskeletal Disorders, 10, 159. https://doi.org/10.1186/1471-2474-10-159

Kusumoto, A., Suzuki, T., Kumakura, C., \& Ashizawa, K. (1996). A Comparative Study of Foot Morphology between Filipino and Japanese Women, with Reference to the Significance of a Deformity Like Hallux Valgus as a Normal Variation. Annals of Human Biology, 23, 373-385. https://doi.org/10.1080/03014469600004622

Lee, C. H., Lee, S., Kang, H., Jung, D. E., Song, Y. M., Lee, K., Lee, K., Hwang, J., \& Sung, J. (2014). Genetic Influences on Hallux Valgus in Koreans: The Healthy Twin Study. Twin Research and Human Genetics, 17, 121-126. https://doi.org/10.1017/thg.2014.10

Lieberman, D. E., Venkadesan, M., Werbel, W. A., Daoud, A. I., D’Andrea, S., Davis, I. S., Mang'eni, R. O., \& Pitsiladis, Y. (2010). Foot Strike Patterns and Collision Forces in Habitually Barefoot versus Shod Runners. Nature, 463, 531-535. https://doi.org/10.1038/nature08723

Lythgo, N., Wilson, C., \& Galea, M. (2009). Basic Gait and Symmetry Measures for Primary School-Aged Children and Young Adults Whilst Walking Barefoot and with Shoes. Gait Posture, 30, 502-506. https://doi.org/10.1016/j.gaitpost.2009.07.119

Matsuda, S., Kasuga, K., Hanai, T., \& Demura, T. (2016). Relationship between Children' Toes and Kinderegartens' Barefoot Policy. Advances in Physical Education, 6, 195-204. https://doi.org/10.4236/ape.2016.63021

Matsuda, S., Kasuga, K., Hanai, T., Demura, T., \& Futabayashi, K. (2016). Relation between Anterior-Posterior Foot Pressure Ratio and Kindergartens' Barefoot Policy. Advances in Physical Education, 6, 328-338. https://doi.org/10.4236/ape.2016.64033 
Matsuda, S., Kasuga, K., Hanai, T., Demura, T., \& Komura, K. (2016). The Effect of the Kindergarten Barefoot Policy on Preschool Children's Toes. Journal of Physiological Anthropology, 36, 4. https://doi.org/10.1186/s40101-016-0097-3

Menz, H. B., Roddy, E., Marshall, M., Thomas, M. J., Rathod, T., Peat, G. M., \& Croft, P. R. (2016). Epidemiology of Shoe Wearing Patterns over Time in Older Women: Associations with Foot Pain and Hallux Valgus. The Journals of Gerontology. Series A, Biological Sciences and Medical Sciences, 71, 1682-1687.

https://doi.org/10.1093/gerona/glw004

Nguyen, U. S., Hillstrom, H. J., Li, W., Dufour, A. B., Kiel, D. P., Procter-Gray, E., Gagnon, M. M., \& Hannan, M. T. (2010). Factors Associated with Hallux Valgus in a Population-Based Study of Older Women and Men: The MOBILIZE Boston Study. Osteoarthritis Cartilage, 18, 41-46. https://doi.org/10.1016/j.joca.2009.07.008

Okuda, H., Juman, S., Ueda, A., Miki, T., \& Shima, M. (2014). Factors Related to Prevalence of Hallux Valgus in Female University Students: A Cross-Sectional Study. Journal of Epidemiology, 24, 200-208. https://doi.org/10.2188/jea.JE20130110

Otsuka, R., Yatsuya, H., Miura, Y., Murata, C., Tamakoshi, K., Oshiro, K., Nishio, N., Ishikawa, M., Zhang, H. M., Shiozawa, M., Kobayashi, A., Ito, M., Hori, Y., Kondo, T., \& Toyoshima, H. (2003). Association of Flatfoot with Pain, Fatigue and Obesity in Japanese over Sixties. Nihon Koshu Eisei Zasshi, 50, 988-998.

Rao, U. B., \& Joseph, B. (1992). The Influence of Footwear on the Prevalence of Flat Foot. A Survey of 2300 Children. The Journal of Bone and Joint Surgery. British Volume, 74, 525-527. https://doi.org/10.1302/0301-620X.74B4.1624509

Riddiford-Harland, D. L., Steele, J. R., \& Storlien, L. H. (2000). Does Obesity Influence Foot Structure in Prepubescent Children? International Journal of Obesity and Related Metabolic Disorders, 24, 541-544. https://doi.org/10.1038/sj.ijo.0801192

Sachithanandam, V., \& Joseph, B. (1995). The Influence of Footwear on the Prevalence of Flat Foot. A Survey of 1846 Skeletally Mature Persons. The Journal of Bone and Joint Surgery. British Volume, 77, 254-257. https://doi.org/10.1302/0301-620X.77B2.7706341

Sato, M., Umemura, M., \& Masaki, S. (2003). Study of Valgus Angles of Great Toe in the Young Adults-Comparison to the Former Study Done 10 Years Ago. Kutsuno Igaku, 17, 51-53. (In Japanese)

Shimoeda, K., Sato, M., \& Sano, S. (1995). A Morphological Study on Children's Foot Growth and Tendency toward Hallux Valgus. Journal of Musculaskeletal System, 8, 1081-1096.

Tashiro, Y., Fukumoto, T., Uritani, D., Matsumoto, D., Nishiguchi, S., Fukutani, N., Adachi, D., Hotta, T., Morino, S., Shirooka, H., Nozaki, Y., Hirata, H., Yamaguchi, M., \& Aoyama, T. (2015). Children with Flat Feet Have Weaker Toe Grip Strength than Those Having a Normal Arch. Journal of Physical Therapy Science, 27, 3533-3536. https://doi.org/10.1589/jpts.27.3533

Tsung, B. Y., Zhang, M., Fan, Y. B., \& Boone, D. A. (2003). Quantitative Comparison of Plantar Foot Shapes under Different Weight-Bearing Conditions. Journal of Rehabilitation Research and Development, 40, 517-526. https://doi.org/10.1682/JRRD.2003.11.0517

Volpon, J. B. (1994). Footprint Analysis during the Growth Period. Journal of Pediatric Orthopaedics, 14, 83-85. https://doi.org/10.1097/01241398-199401000-00017

Wegener, C., Hunt, A. E., Vanwanseele, B., Burns, J., \& Smith, R. M. (2011). Effect of Children's Shoes on Gait: A Systematic Review and Meta-Analysis. Journal of Foot and Ankle Research, 4, 3. https://doi.org/10.1186/1757-1146-4-3 
Wolf, S., Simon, J., Patikas, D., Schuster, W., Armbrust, P., \& Doderlein, L. (2008). Foot Motion in Children Shoes: A Comparison of Barefoot Walking with Shod Walking in Conventional and Flexible Shoes. Gait Posture, 27, 51-59.

https://doi.org/10.1016/j.gaitpost.2007.01.005 